\title{
Education
}

\section{Leading Organizational Learning}

Jessica C. Wells, MA

\section{Abstract}

\section{Description}

A learning organization engages their teams to garner a commitment to learning and leverage organizational knowledge thereby positioning themselves better for future innovation. Organizations that focus on interrelated learning at the individual, group or team and organizational levels are optimally positioned to maximize organizational competitiveness in dynamic, competitive environments. A leader's responsibility is to devote more effort to guide the organization's continuous development, members, and themselves. Through constant learning, the organization can leverage learning to create competitive strategies while cultivating transformative opportunities. However, successful learning outcomes are not the product of any individual or leader, and instead, the collective work of all involved. Leaders focused on organizational learning realize the dynamic nature of operating a business in a competitive environment and encourage members to seek feedback, new educational opportunities, open communication, and innovative problem-solving strategies, the combination of which enable the collective organization to not just survive but thrive.

\section{Keywords}

leadership; organizational learning; organization and administration; team learning; implicit knowledge; explicit knowledge; knowledge management; leading change; information dissemination; learning/organization and administration

\section{Introduction}

Leaders are responsible for developing and deploying an integration strategy aimed at helping organizational members relate to others, coordinate their efforts, build commitments and develop extended social networks, thereby emphasizing the importance of organizational learning. ${ }^{1}$ To guide these efforts, leaders need to cultivate their leadership philosophy, as organizational members take their cue from leaders on what is important to the organization, thus purposely leading organizational learning. Fundamentally, organizational learning promotes adaptive decision-making based on members' experiences, resulting in changes to goals, processes and strategic direction. ${ }^{2} \mathrm{~A}$ learning organization engages their teams to garner a commitment to learning and leverage organizational knowledge and positions themselves better for future innovation. ${ }^{3}$ Organizations that focus on interrelated learning at the individual, group or team and organizational levels are optimally positioned to maximize organizational competitiveness. ${ }^{4}$ Cultivating a learning organization requires leaders to establish and adopt knowledge management and team management strategies while engaging learners to embrace change. The pace and complexity of necessary advancements impact how both leaders and followers view change processes and engage in organizational learning. As a result, leaders must be skilled in implementing and managing change to motivate and expand their organization's absorptive capacity. ${ }^{5}$ This article provides an overview of organizational learning, discusses the importance of team learning and knowledge management, and emphasizes a leader's responsibility to develop a progressive learning environment.

\section{Organizational Learning}

Organizational learning and a learning organization are not interchangeable concepts.

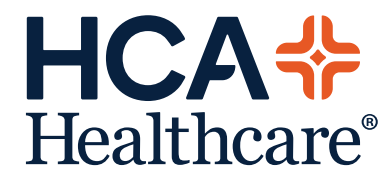

www.hcahealthcarejournal.com

(c) 2021 HCA Physician Services, Inc. d/b/a Emerald Medical Education

\author{
HCA Healthcare \\ Journal of Medicine
}


A learning organization is an entity with the capacity to successfully engage in learning processes (organizational learning) that leads to organizational prosperity. ${ }^{6}$ This differentiation emphasizes the importance of a leader's focus on each learner while leveraging outcomes for collective use. Additionally, organizational learning requires leaders to concentrate on changes in collective knowledge, organizational structures and behaviors to instill adaptive practices. ${ }^{\top}$ Organizational learning is essential to decision-making by requiring feedback loops in both stable and dynamic conditions, thereby highlighting the strategic role of continuous learning to organizational success. ${ }^{6}$

The process and outcomes of individual learning can be difficult to discern and quantify, countering the perception that organizational learning is merely the sum of individual learning. ${ }^{7}$ More importantly, organizational learning outcomes are jointly shared associations, cognitive systems and memories by members of the organization. ${ }^{7}$ However, the process of learning does not immediately translate to adaptive behaviors or adoption of new knowledge, but requires organizations to examine the structures supporting organizational learning ${ }^{7}$ and ensure a safe climate for member self-reflection. ${ }^{8}$

\section{Team Learning as a Conduit to Organizational Learning}

Teams are increasingly deployed to tackle complex problems in organizations because the dynamic, competitive environment requires collective knowledge and leveraging multiple members' expertise. ${ }^{9}$ Due to workplace knowledge generated through social constructs, team-based learning is often difficult to describe and underappreciated..$^{10}$ Significant to team-based learning's success is the deliberate management of commonly held beliefs, values, purposes and structures while emphasizing the importance of building relationships within a group..$^{10}$ To truly cultivate organizational learning, leaders should focus on group membership and cross-fertilization of team learning."

Team learning is group or organization initiated by developing shared knowledge and skills." Team learning can manifest in outcomes improvement, task mastery or optimizing team processes. ${ }^{11}$ Additionally, team learning high- lights the role of team member experiences, collaborative processes and collective learning for outcome improvement." In contrast, task mastery is the focus of knowledge coordination to leverage team member expertise to accomplish a specific purpose." However, the team process is a combination of both the means by which teams learn as well as what they learn." Team processes require understanding both cognitive and social processes that aid or prohibit the contribution of shared conception and mental models to team learning behaviors and effectiveness. ${ }^{9}$ Learning organizations that seek to leverage effective team learning for success must be intentional in developing outcome improvement, task mastery and, most importantly, team processes.

\section{Implicit and Explicit Knowledge} Knowledge is multifaceted as it can be tacit and explicit. ${ }^{12}$ Tacit or implicit knowledge influences decision-making and behaviors unconsciously with little cognitive effort..$^{13}$ Tacit knowledge can be technical or cognitive and is often considered highly subjective, incorporating unique perspectives and underlying belief systems. ${ }^{13}$ Tacit knowledge accounts for nearly two-thirds of work-related information, presented in casual conversations, stories, mentoring conversations and apprenticeship constructs. ${ }^{13}$ Tacit knowledge continuously develops and is often migratory as individuals move throughout the organization, allowing knowledge to exist in varied contexts. ${ }^{14}$ Tacit knowledge is an important and competitive asset within an organization but is often difficult to codify and operationalize. ${ }^{6}$

Explicit knowledge, however, is more formal than tacit knowledge. Explicit knowledge is usually found in procedural manuals and technical documentation, with content gained through prescribed structures such as classrooms and training workshops..$^{13}$ Explicit knowledge is more transferrable than tacit knowledge as it is organized in easily translatable formats. ${ }^{13}$ While the principal difference between tacit and explicit knowledge owes to how knowledge develops, in actuality, knowledge exists on a continuum where tacit knowledge underlays explicit knowledge, and explicit knowledge allows us to apply tacit knowledge. ${ }^{15}$ 


\section{The Importance of Knowledge \\ Management}

The collective knowledge of organizational members is considered the most important asset of an organization yet is extraordinarily challenging to harness. ${ }^{13}$ Valuable resources are wasted unless leaders champion efforts to gather, transform and share knowledge among organizational members and teams..$^{13}$ Knowledge management requires the acquisition, creation and refinement of organizational assets such as manuals, best practices, procedures, processes and incident solutions. ${ }^{16}$ Organizations are expected to manage knowledge into well-organized systems that are accurate and easily accessible. ${ }^{13}$ The integration of knowledge management in organizational norms is essential for improving efficiency and effectiveness, innovation and responsiveness while achieving competitive advantage and developing a knowledge intense culture. ${ }^{17}$ Critical to any knowledge management system's success is the capability for an organization to integrate the stored knowledge into organizational processes and help members both understand and utilize the system in their daily occupation. ${ }^{12}$

\section{Linking Organizational Learning and Knowledge Management}

The globalization of many businesses provides a plethora of opportunities for organizations to realize success by developing knowledge and information-intensive systems and infrastructure. ${ }^{2}$ Knowledge and information sharing networks shift focus away from reactive business strategies and enable organizations to construct future environments instead of adapting to external pressures. ${ }^{2}$ These networks allow for incorporating available knowledge into business practices in anticipation of external pressures and shifts. Business processes that require an organizational member to make decisions based on interdependent experiences, colleagues and knowledge resources rely on organizational strategies for knowledge asset development and dissemination. Organizations that highlight the value of these strategies in organizational learning, especially in knowledge-intensive industries such as healthcare and finance, will realize more optimal adherence to the required processes..$^{18}$ Furthermore, organizational learning and knowledge are closely intertwined, reliant on leaders acknowledging and embracing a culture where learning and knowledge creation are continuous, reciprocal processes. ${ }^{14}$ Leaders must emphasize knowledge sharing among members in a consumable fashion with a focus on actionable learning.

\section{Leading Change Through Organizational Learning} Organizational change and change management are increasingly critical for success due to an ever-evolving competitive environment in which organizational change is not separate from organizational strategy. ${ }^{19}$ The pace and complexity of necessary advancement impact how members view change processes and implications for organizational learning. Change is not an isolated linear event but a continuous realignment in anticipation of or in response to changing environments. ${ }^{20} \mathrm{~A}$ leader's role in planned change is to facilitate essential learning and to emphasize iterative reflection to create impactful interactions cultivated through organizational learning. ${ }^{21}$ There is an inherent complexity in developing the culture, leadership skills, follower engagement, commitment and organizational capacity to embrace change, which requires a continuous focus on organizational learning. Perhaps, a more viable approach to change is through organizational learning in which individuals continually interpret and adjust to external and internal pressures. ${ }^{19}$

Fundamentally, organizational change is predicated on members who individually and collectively seek the organization's best interests by consistently centering on continuous, adaptive learning for the benefit of the organization and the world around them. ${ }^{21}$ For organizations to successfully navigate change, members must not be manipulated or coerced and, more importantly, thoroughly understand the motivation for change. ${ }^{21} \mathrm{~A}$ successful change management philosophy, then, highlights the importance of member iterative reflection and learning to facilitate change. Accordingly, the organizational change would not be successful without a focus on organizational learning principles. 


\section{Leadership Philosophy and Organizational Learning}

A leader's responsibility is to devote more effort to guide the organization's continuous development, members and themselves. ${ }^{2}$ Through constant learning, the organization can leverage learning to create competitive strategies while cultivating transformative opportunities. ${ }^{2}$ Leaders critical factors to successful learning by promoting the value of change to followers through their communications, facilitation of the process and behavioral adoption of new or innovative practices. ${ }^{22}$ However, successful learning outcomes are not the product of any individual or leader and instead, are the collective work of all involved. ${ }^{23}$ As people embark on change, they develop new perspectives and make discoveries about themselves and their team members, thereby creating shared experiences. $^{2}$

For leadership to successfully influence outcomes, leaders must demonstrate the value of continuous self-development to both their members and themselves. Cumulative and holistic learning within an organization requires a new form of leader, defined as someone who acts as a designer, steward and teacher. ${ }^{3}$ Furthermore, leaders in learning organizations need to be individuals willing and able to build organizations where members fundamentally understand complexity, clarify vision and improve shared mental models. ${ }^{3}$ To continually expand, leaders and teams must be adaptable and agile. Through a reflective and continuous learning mentality, a leader becomes the role model for others in the organization to evolve toward contributing their experiences and learnings to enhance the organizational learning environment.

\section{Conclusion}

The global, competitive environment in which organizations compete requires leaders who are adaptive, highly communicative and have a high acumen for continuous, in situ learning. Leaders who possess these attributes and the capability to serve as a positive role model for organizational members create foundational elements for their organizations to manage the myriad of forces slowing successful progress. Moreover, a leader's commitment to knowledge management demonstrates to members the importance of information retention and how the past informs the present and guides the future. Through clear documentation of this lineage and the learnings gained over time, members consistently reference change. Leaders focused on organizational learning realize the dynamic nature of operating a business in a competitive environment and encourage members to seek feedback, new educational opportunities, open communication, and innovative problem-solving strategies, the combination of which enable the collective organization to not just survive but thrive.

\section{Conflicts of Interest}

The author declares she has no conflicts of interest.

The author is an employee of HCA Healthcare Graduate Medical Education, an organization affiliated with the journal's publisher.

This research was supported (in whole or in part) by HCA Healthcare and/or an HCA Healthcare affiliated entity. The views expressed in this publication represent those of the author(s) and do not necessarily represent the official views of HCA Healthcare or any of its affiliated entities.

\section{Author Affiliation}

1. HCA Healthcare Graduate Medical Education, Brentwood, TN

\section{References}

1. Day DV. Leadership development: A review in context. The Leadership Quarterly. 2000;11(4):581-613. https://doi.org/10.1016/S10489843(00)00061-8

2. Calhoun MA, Starbuck WH, Abrahamson E. Fads, Fashions, and the Fluidity of Knowledge: Peter Senge's 'the Learning Organization.' In: Easterby-Smith M, Lyles MA, eds. Handbook of Organizational Learning and Knowledge Management. 2nd ed. John Wiley \& Sons; 2012:225-248. https://doi.org/10.1002/9781119207245.ch11

3. Senge, PM. The Fifth Discipline: The Art \& Practice of the Learning Organization. Doubleday; 2006.

4. Barba Aragón MI, Jiménez Jiménez, D, Sanz Valle R. Training and performance: The mediating role of organizational learning. Business Research Quarterly. 2014:17(3):161-173. https://doi. org/10.1016/i.cede.2013.05.003 
5. Bryman A, Collinson D, Grint K, Jackson B, Uhl-Bien M, eds. The SAGE handbook of leadership. London: SAGE Publications; 2011.

6. Easterby-Smith M, Lyles MA, eds. Handbook of Organizational Learning \& Knowledge Management. 2nd ed. John Wiley \& Sons; 2015.

7. Fiol CM, Lyles MA. Organizational Learning. The Academy of Management Review. 1985;10(4):803. https://doi.org/10.5465/amr.1985.4279103

8. Heorhiadi A, La Venture K, Conbere JP. What do organizations need to learn to become learning organizations? OD Practitioner. 2014;46(2):5-9.

9. Van den Bossche P, Gijselaers W, Segers M, Woltjer G, Kirschner P. Team learning: building shared mental models. Instructional Science. 2011;39(3):283-301. https://doi.org/10.1007/s11251010-9128-3

10. Boud D, Garrick J, eds. Understanding learning at work. London: Routledge; 1999.

11. Roloff KS, Woolley AW, Edmondson AC. (2015). The Contribution of Teams to Organizational Learning. In: Easterby-Smith M, Lyles MA, eds. Handbook of Organizational Learning and Knowledge Management. 2nd ed. John Wiley \& Sons; 2012:225-248. https://doi. org/10.1002/9781119207245.ch12

12. Von Krogh G. Knowledge Sharing in Organizations: The Role of Communities. In: EasterbySmith M, Lyles MA, eds. Handbook of Organizational Learning and Knowledge Management. 2nd ed. John Wiley \& Sons; 2012:225-248. https://doi. org/10.1002/9781119207245.ch19

13. Smith EA. The role of tacit and explicit knowledge in the workplace. Journal of Knowledge Management. 2001;5(4):311-321. http://doi. org/10.1108/13673270110411733

14. Rowley J. (2001). Knowledge management in pursuit of learning: the Learning with Knowledge Cycle. Journal of Information Science. 2001;27(4):227-237. https://doi.org/10.1177/016555 150102700406

15. Tsoukas H. How should we understand tacit knowledge? A phenomenological view. In: Easterby-Smith M, Lyles MA, eds. Handbook of Organizational Learning and Knowledge Management. 2nd ed. John Wiley \& Sons; 2012:225-248. https://doi.org/10.1002/9781119207245.ch21

16. Sathishkumar AS, Karthikeyan P. A Study on Effective Organizational Learning Through Knowledge Management Model. CLEAR International Journal of Research in Commerce \& Management. 2017;8(4):34-36.

17. Imran MK, Ilyas M, Fatima T. Achieving organizational performance through knowledge management capabilities: Mediating role of organizational learning. Pak J Commer Soc Sci. 2017;11(1):105-124.

18. Little TA, Deokar AV. Understanding knowledge creation in the context of knowledge-intensive business processes. Journal of Knowledge
Management. 2016:20(5):858-879. https://doi. org/10.1108/jkm-11-2015-0443

19. Todnem By R. Organisational change management: A critical review. Journal of Change Management. 2005;5(4):369-380. https://doi. org/10.1080/14697010500359250

20. Burnes B, Bargal D. Kurt Lewin: 70 years on. Journal of Change Management. 2017;17(2):91100. http://dx.doi.org/10.1080/14697017.2017.129 $\underline{9371}$

21. Burnes B. Kurt Lewin and the Harwood studies: The foundations of OD. The Journal of Applied Behavioral Science. 2007;43(2):213-231. https:// doi.org/10.1177/0021886306297004

22. Rushmer R, Kelly D, Lough M, Wilkinson JE, Davies HT. Introducing the Learning Practice-III. Leadership, empowerment, protected time and reflective practice as core contextual conditions. J Eval Clin Pract. 2004;10(3):399-405. https://doi. org/10.1111/j.1365-2753.2004.00466.x

23. Todnem By R, Hughes M, Ford J. Change Leadership: Oxymoron and Myths. Journal of Change Management. 2016;16(1):8-17. https://doi.org/10.1 080/14697017.2016.1137425 